\title{
BMJ open The incidence of rugby-related catastrophic injuries (including cardiac events) in South Africa from 2008 to 2011: a cohort study
}

\author{
James Craig Brown, ${ }^{1,2}$ Mike I Lambert, ${ }^{1}$ Evert Verhagen, ${ }^{2}$ Clint Readhead, ${ }^{3}$ \\ Willem van Mechelen, ${ }^{1,2}$ Wayne Viljoen ${ }^{3}$
}

To cite: Brown JC, Lambert MI, Verhagen E, et al. The incidence of rugbyrelated catastrophic injuries (including cardiac events) in South Africa from

2008 to 2011: a cohort study. BMJ Open 2013;3: e002475. doi:10.1136/ bmjopen-2012-002475

- Prepublication history for this paper are available online. To view these files please visit the journal online (http://dx.doi.org/10.1136/ bmjopen-2012-002475).

Received 10 December 2012 Revised 22 January 2013 Accepted 28 January 2013

This final article is available for use under the terms of the Creative Commons Attribution Non-Commercial 2.0 Licence; see

http://bmjopen.bmj.com

${ }^{1}$ UCT/MRC Research Unit for Exercise Science and Sports Medicine, Department of Human Biology, University of Cape Town, Cape Town, South Africa

${ }^{2}$ Department of Public and Occupational Health, EMGO Institute for Health and Care Research, VU University Medical Center, Amsterdam, The Netherlands

${ }^{3}$ South African Rugby Union (SARU), Cape Town,

South Africa

Correspondence to James Craig Brown; jamesbrown06@gmail.com

\section{ABSTRACT}

Objectives: To establish an accurate and comprehensive injury incidence registry of all rugby union-related catastrophic events in South Africa between 2008 and 2011. An additional aim was to investigate correlates associated with these injuries.

Design: Prospective.

Setting: The South African amateur and professional rugby-playing population.

Participants: An estimated 529483 Junior and 121663 Senior rugby union ('rugby') players (population at risk).

Outcome measures: Annual average incidences of rugby-related catastrophic injuries by type (cardiac events, traumatic brain and acute spinal cord injuries (ASCls)) and outcome (full recoveriesfatalities). Playing level (junior and senior levels), position and event (phase of play) were also assessed.

Results: The average annual incidence of ASCls and Traumatic Brain Injuries combined was 2.00 per 100000 players ( $95 \% \mathrm{Cl} 0.91$ to 3.08) from 2008 to 2011. The incidence of ASCls with permanent outcomes was significantly higher at the Senior level (4.52 per 100000 players, $95 \% \mathrm{Cl} 0.74$ to 8.30 ) than the Junior level $(0.24$ per 100000 players, $95 \% \mathrm{Cl}$ 0 to 0.65 ) during this period. The hooker position was associated with $46 \%$ ( $n=12$ of 26 ) of all permanent ASCl outcomes, the majority of which (83\%) occurred during the scrum phase of play.

Conclusions: The incidence of rugby-related catastrophic injuries in South Africa between 2008 and 2011 is comparable to that of other countries and to most other collision sports. The higher incidence rate of permanent ASCls at the Senior level could be related to the different law variations or characteristics (eg, less regular training) compared with the Junior level. The hooker and scrum were associated with high proportions of permanent ASCls. The BokSmart injury prevention programme should focus efforts on these areas (Senior level, hooker and scrum) and use this study as a reference point for the evaluation of the effectiveness of the programme.

\section{ARTICLE SUMMARY}

Article focus

- Incidence of all catastrophic rugby-related injuries in South Africa between 2008 and 2011 and correlates that accounted for a high proportion of both all and permanent acute spinal cord injuries.

- This study serves as a reference point for evaluating the effectiveness of the BokSmart programme going forward.

Strengths and limitations of this study

- The strengths of the paper were the prospective design and comprehensive inclusion criteria for catastrophic injuries.

- Another strength was the novel statistical comparison and the finding of a higher incidence of catastrophic injury at the Senior level.

- A weakness of the study was the fact that the player numbers were assumed to have been constant for the entire period of investigation (2008-2011).

Key messages

- The rate of catastrophic injuries in South African rugby is comparable to other collision sports.

- Catastrophic injuries occurred more often in Senior than Junior players. The hooker positional grouping and scrum phase of play were associated with high proportions of catastrophic injury.

- Current findings should guide and focus BokSmart's prevention efforts.

\section{INTRODUCTION}

While catastrophic events rarely occur in sport, ${ }^{1}$ the long-term consequences and implicit severity of these events make them the most devastating of all injuries to the player, their family and friends. ${ }^{2}$ Up until the third decade of life, sport is associated with a large proportion of all catastrophic spinal 
injuries. Of all sports, collision games such as American Football, Ice Hockey and Rugby account for a large proportion of these sport-related catastrophic events. ${ }^{3-5}$ Furthermore, Rugby Union (henceforth 'Rugby') is currently the most popular collision sport worldwide ${ }^{6}$ and has an enormous participant base with 118 active international Unions (http://www.irb.com).

Despite these participation levels, a recent review concluded that the level of risk of suffering a catastrophic injury while playing rugby in the UK was 'acceptable' (0.8 per 100000 participants). Furthermore, this annual incidence was not higher than that of other collision sports such as Rugby League (1.9 per 100000 participants), Ice Hockey (4.1 per 100000 participants) or American Football (1.0 per 100000 participants). ${ }^{1}$ For South Africa in 2007, the average annual incidence of rugby-related permanently disabling spinal cord injury was estimated to be lower (0.6 per 100000 participants) than other rugby-playing nations such as New Zealand, Ireland and Australia. ${ }^{17}$ Despite these 'endorsements' of the relatively low risk of catastrophic injury associated with rugby, an early South African study ${ }^{8}$ concluded that $56 \%$ of all rugby-related spinal cord injuries reported could potentially have been prevented. It is these predictable and preventable catastrophic injuries that are the priority focus for injury prevention strategies. ${ }^{59}$

As a result, New Zealand's RugbySmart programme (http://www.nzrugby.co.nz/the_game/safety/rugbysmart) was developed and proved successful in reducing catastrophic injuries. ${ }^{191011}$ Based on this success, the South African Rugby Union (SARU) developed their own programme, BokSmart (http://www.boksmart.com), ${ }^{12} 13$ modelling it on a comparable intervention approach to New Zealand with additional components to suit the South African rugby landscape, making it an example of a national sports organisation intervention. ${ }^{14}$ Other catastrophic injury prevention strategies for rugby include Rugbyready (International Rugby Board (IRB)), Smart Rugby (Australia) and Tackling Safety (England). ${ }^{1}$ To evaluate the effectiveness of the BokSmart programme, one first needs to establish the incidence and severity of catastrophic events. ${ }^{15}$

Therefore, the primary aim of this paper was to establish an accurate and comprehensive injury incidence registry of all rugby union-related catastrophic events in South Africa between 2008 and 2011. An additional aim was to investigate correlates associated with these injuries.

\section{METHODS}

Data for this study were collected through the BokSmart programme, which is a joint initiative between the SARU (http://www.sarugby.co.za) and the Chris Burger/Petro Jackson Player's Fund (CBPJPF) (http://www.playersfund. org.za). The CBPJPF is a non-profit public benefit organisation, developed to aid players who have been permanently disabled while playing rugby in South Africa. ${ }^{16}$ Permission to analyse the data was obtained, with SARU and CBPJPF's permission, by the UCT Human Research Ethics Committee.

This is a descriptive study in which injury incidences are described from data that were collected prospectively. Risk factors between players that suffered catastrophic events and those that did not suffer these events were not investigated. The following definitions were adopted for this manuscript (a more detailed description of the game of rugby union is available elsewhere ${ }^{17}$ ):

\section{Catastrophic injury}

BokSmart and the CBPJPF use the following definition for recording catastrophic injuries:

Any head, neck, spine or brain injury that is lifethreatening, or has the potential to be permanently debilitating and results in the emergency admission of a rugby player to a hospital or medical care center.

An event that satisfied the above definition, but was established to be a cardiac-related injury (not head, neck, spine or brain), was also recorded and classified as a 'cardiac event'. Injuries (includes cardiac events) represented both amateur and professional levels. Catastrophic injuries were classified into three different groups: (1) Acute Spinal Cord Injury (ASCI), (2) Traumatic Brain Injury (TBI) and (3) Cardiac events. ASCIs were further grouped into outcomes, listed in the order of increasing severity: near miss (full recovery expected, ambulant), neurological deficit (some deficit remains, may walk with or without the requirement of assistive devices), quadriplegic and fatal. TBI outcomes were divided into, with increasing severity: fully recovered, disability (remaining neurological deficit) and fatal. ASCIs and TBIs were further grouped into "nonpermanent' (near misses/fully recovered) and 'permanent' (residual disability, including fatalities). Non-fatal permanent injuries-neurological deficit (ASCI), quadriplegia (ASCI), residual disability (TBI) — would be classified as morbidities and all fatalities would be classified as mortalities.

The outcomes presented are the hospital-confirmed diagnoses within 1 month after the initial injury date as this time frame was thought to be able to provide a more accurate diagnosis.

\section{Incidence}

The numerator was calculated as the number of catastrophic injuries and the denominator was the population at risk (total number of rugby players in South Africa). These player numbers were obtained from the IRB website (http://www.irb.com/unions/index.html). Incidences were presented as an annual average (over the 4 year period) per 100000 players.

\section{Age group}

This term distinguished between Juniors and Seniors. 'Junior' is synonymous with 'schoolboy' in the South 
African context (under-7 to under-19), and included 'pre-teen' and 'teen' males and females (as per the IRB website). 'Senior' comprised anyone who was not in the definition for 'Junior' for males and females (older than under-19) and also included both amateurs and professionals. This term was used to describe the age group of the match where the injury event occurred, regardless of whether the player was legitimately participating in that age group at the time.

\section{Event}

This term described the phase of play where the injury occurred and included scrum, ruck, tackle (this included both ball-carriers and tacklers) and collisions (an unintentional or intentional clash-which is distinct from a 'tackle').

\section{Positional grouping}

Owing to the small sample sizes, the 15 general positions were grouped into nine positional groupings as per Durandt et al ${ }^{18}$ : prop (loose-head and tight head prop; 2 positions), hooker (1 position), lock (left and right lock; 2 positions), loose-forward (open-side flank, blindside flank and eighth man; 3 positions), scrumhalf (1 position), flyhalf (1 position), centre (inside and outside centre; 2 positions), wing (left and right wing; 2 positions) and fullback ( 1 position).

\section{Statistics}

Incidences with 95\% CIs were calculated using the standard formulae ${ }^{19}$ suggested for rugby union injury studies. ${ }^{20}$ Incidences were considered significantly different if the 95\% CIs did not overlap. Any negative lower
95\% confidence limits were presented as ' 0 '. To confirm these comparisons using $95 \%$ CIs, $p$ values were also calculated for comparisons of Junior and Senior groups using VRP injury statistics software. ${ }^{8}{ }^{21}$ If a $\mathrm{p}$ value was less than 0.05 , the difference between groups was considered significantly different, even if the overlap existed between $95 \%$ CIs. $^{22}$

All presented proportions were calculated after excluding missing data (if present) for a particular sectionthe denominator is always indicated to remove ambiguity.

\section{RESULTS}

Since 2008, there have been 54 catastrophic injuries (24 in Juniors and 30 in Seniors) recorded in total in South Africa (table 1), the majority of which $(n=45)$ were ASCIs. In Juniors, the highest number of injuries occurred in $2009(n=8)$, while for Seniors the highest number $(n=9)$ occurred in both 2009 and 2010.

Owing to the small changes in numbers per year, incidences were calculated on the annual average of injuries over the 4-year period (table 1).

With an estimated 651146 players at both levels (Junior: $n=529$ 483; Senior: $n=121$ 663) in South Africa, the average annual incidence for all catastrophic injuries (TBI, cardiac events and ASCIs) was 2.07 per 100000 players (95\% CI 0.97 to 3.18). Senior players had a significantly higher incidence of these events $(6.16,95 \%$ CI 1.75 to 10.58$)$ than Junior players $(1.13,95 \%$ CI 0.23 to 2.04; $\mathrm{p}=0.03$ ). The average annual incidence for all TBIs and ASCIs combined (excluding cardiac events) was also significantly higher at the Senior level $(5.96,95 \%$ CI 1.62 to 10.30$)$ than the Junior level $(1.09,95 \%$ CI 0.20 to

Table 1 Absolute numbers of serious/catastrophic injuries in Junior and Senior Rugby levels in South Africa by year, between 2008 and 2011 (4 years, inclusive)

\begin{tabular}{|c|c|c|c|c|c|c|c|c|c|c|c|c|}
\hline \multirow[b]{2}{*}{ Type of injury } & \multicolumn{2}{|l|}{2008} & \multicolumn{2}{|l|}{2009} & \multicolumn{2}{|l|}{2010} & \multicolumn{2}{|l|}{2011} & \multicolumn{2}{|l|}{ Total } & \multicolumn{2}{|l|}{$\begin{array}{l}\text { Annual } \\
\text { average }\end{array}$} \\
\hline & Junior & Senior & Junior & Senior & Junior & Senior & Junior & Senior & Junior & Senior & Junior & Senior \\
\hline \multicolumn{13}{|c|}{ Acute spinal cord injury (ASCI) $(n=45)$} \\
\hline $\begin{array}{l}\text { 'Near miss' (full } \\
\text { recovery/ambulant) }\end{array}$ & 2 & 1 & 4 & 0 & 3 & 1 & 3 & 1 & 12 & 3 & 3.00 & 0.75 \\
\hline Neurological deficit & 1 & 1 & 0 & 2 & 0 & 4 & 2 & 3 & 3 & 10 & 0.75 & 2.5 \\
\hline Quadriplegics & 1 & 1 & 0 & 3 & 0 & 2 & 1 & 3 & 2 & 9 & 0.50 & 2.25 \\
\hline Fatal & 0 & 0 & 0 & 1 & 0 & 1 & 0 & 1 & 0 & 3 & 0 & 0.75 \\
\hline Not provided & 1 & 0 & 0 & 1 & 1 & 0 & 0 & 0 & 2 & 1 & 0.50 & 0.25 \\
\hline \multicolumn{13}{|c|}{ Traumatic brain injury $(T B I)(n=7)$} \\
\hline Fully recovered & 0 & 0 & 2 & 0 & 0 & 0 & 0 & 0 & 2 & 0 & 0.50 & 0 \\
\hline Disability & 1 & 0 & 0 & 0 & 0 & 0 & 0 & 0 & 1 & 0 & 0.25 & 0 \\
\hline Fatal & 0 & 1 & 1 & 1 & 0 & 1 & 0 & 0 & 1 & 3 & 0.25 & 0.75 \\
\hline \multicolumn{13}{|l|}{ Cardiac events $(n=2)$} \\
\hline Fatal & 0 & 0 & 1 & 1 & 0 & 0 & 0 & 0 & 1 & 1 & 0.25 & 0.75 \\
\hline Total & 6 & 4 & 8 & 9 & 4 & 9 & 6 & 8 & 24 & 30 & 6.00 & 7.50 \\
\hline
\end{tabular}

Injuries are divided into type: Acute Spinal Cord Injury (ASCI), Traumatic Brain Injury (TBI) and Cardiac events and clinical outcome (indented below Type of injury)An annual average, which is the total number of events divided by the 4 years, is also provided.

Average is calculated for the 4 years that the data have been collected. 
1.97) $(\mathrm{p}=0.03)($ combined $=2.00$ per 100000 players, $95 \%$ CIs 0.91 to 3.08) between 2008 and 2011. In combination, permanent TBIs and ASCIs occurred significantly more often at the Senior level (5.14 per 100000 players, 95\% CIs 1.11 to 9.16) than the Junior level (0.33 per 100000 players, 95\% CIs: 0 to $0.82 ; \mathrm{p}=0.02)$ between 2008 and 2011 (combined: 1.23 per 100000 players; $95 \%$ CIs: 0.38 to 2.08$)$.

The incidence of TBIs was 0.19 per 100000 Junior players $(95 \%$ CI 0 to 0.56$)$ and 0.62 per 100000 Senior players $(95 \%$ CIs 0 to 2.01$)$. The incidence of cardiac events was 0.05 per 100000 Junior players (95\% CIs 0 to 0.23 ) and 0.21 per 100000 Senior players (95\% CI 0 to 1.01). The point estimates calculated for TBIs and cardiac events should be interpreted with caution due to the low numbers of these events (table 1). Half of the TBIs in Junior players $(50 \%, n=2$ of 4$)$ had full recoveries, while all outcomes in Senior players $(100 \%, n=3)$ were fatal. Both cardiac events to date $(n=2)$ had fatal outcomes.

Owing to the low numbers of cardiac and TBI outcomes $(n=9)$, subsequent analyses only focus on ASCIs.

\section{Correlates of ASCls (TBIs and cardiac events excluded): 2008-2011}

All of the ASCIs were sustained by males. Seven per cent of the ASCIs ( $n=3$ of 42$)$ were fatal, $26 \% \quad(n=11$ of 42$)$ resulted in quadriplegia, $31 \%(\mathrm{n}=13$ of 42$)$ resulted in neurological deficit and the remaining $36 \% \quad(n=15$ of 42) were classified as 'near misses' (outcome not provided in $\mathrm{n}=3$ cases; table 1). Henceforth, for further comparison, outcomes of ASCI were also grouped as either 'Permanent' (neurological deficit, quadriplegia, fatal) or 'Non-Permanent' (near miss).

The Senior level accounted for $58 \%(n=26$ of 45$)$ of all ASCIs. Considering the population at-risk numbers, the average annual incidence of all ASCIs (including 'not provided' outcomes) was significantly higher at the Senior level (5.34 per 100000 players, 95\% CI 1.24 to
9.45) compared with the Junior level (0.90 per 100000 players, 95\% CI 0.09 to $1.70 ; \mathrm{p}=0.04$ ) between 2008 and 2011 (table 2).

In Senior players, $85 \%(n=22$ of 26$)$ of all ASCIs had permanent outcomes (neurological deficit, quadriplegia or fatal) in comparison to $26 \%(n=5$ of 19$)$ in Junior players. When considering the different numbers for the populations at risk, permanent ASCIs occurred significantly more often in Senior players (4.52 per 100000 players; 0.74-8.30) than Junior players $(0.24$ per 100000 players; $0-0.65 ; \mathrm{p}=0.04$; combined: 1.04 per 100000 players, 95\% CI 0.25 to 1.82) between 2008 and 2011 (table 2).

Matches, as opposed to training, were associated with $88 \%(n=38$ of 43$)$ of all ASCIs (information not available for $n=2$ cases). The training injuries occurred either in a scrum $(n=2)$, tackle $(n=2)$ or ruck $(n=1)$. Owing to the low numbers of training injuries and the fact that their mechanisms were similar to those that occurred in matches, these injuries were combined with match injuries for further analyses (figures 1 and 2).

The scrum was involved in $42 \% \quad(n=19$ of 45$)$ of all ASCIs. Sixty-three per cent $(n=12$ of 19) of scrumrelated ASCIs occurred to Senior players, which equates to an incidence of 2.47 injuries per 100000 Senior players (95\% CI 0 to 5.26) between 2008 and 2011. Together, the scrum and tackle accounted for $80 \%$ $(n=36$ of 45$)$ of all ASCIs for both levels combined (Junior and Senior; figure 1A). Eighty-two per cent $(n=14$ of 17; outcome 'not provided' for $n=2)$ of scrum-related injuries had permanent outcomes compared with $50 \%$ of tackle injuries ( $n=8$ of 16 ; outcome 'not provided' for $\mathrm{n}=1$; table $1 \mathrm{~B}$ ). The 14 scrum-related permanent ASCI outcomes equated to an average annual incidence of 0.54 permanent scrum ASCIs per 100000 players (95\% CI 0 to 1.10) between 2008 and 2011.

The Senior age group accounted for $79 \% \quad(n=11$ of 14) of the permanent scrum injuries and $88 \%(n=7$ of 8$)$ of the permanent tackle injuries. Of all the scrum injuries,

Table 2 Average annual incidences (based on IRB estimated numbers) of acute spinal cord injury (ASCI) from 2008-2011 in South Africa (4 years, inclusive). Incidences include $95 \% \mathrm{Cl}$

\begin{tabular}{|c|c|c|c|}
\hline ASCl outcome & $\begin{array}{l}\text { Junior } \\
\text { Incidence }(95 \% \mathrm{Cl})\end{array}$ & $\begin{array}{l}\text { Senior } \\
\text { Incidence }(95 \% \mathrm{Cl})\end{array}$ & $\begin{array}{l}\text { Combined } \\
\text { Incidence }(95 \% \mathrm{Cl})\end{array}$ \\
\hline Permanent (ND+Quad.+Fatal) & 0.24 (0 to 0.65$)$ & $4.52(0.74$ to 8.30$)$ & $1.04(0.25$ to 1.82$)$ \\
\hline Neurological deficit (ND) & 0.14 (0 to 0.46$)$ & 2.05 (0 to 4.60$)$ & 0.50 (0 to 1.04$)$ \\
\hline Quadriplegics (Quad.) & 0.09 (0 to 0.36$)$ & 1.85 (0 to 4.27$)$ & 0.42 (0 to 0.92 ) \\
\hline Fatal & $0(-)$ & 0.62 (0 to 2.01$)$ & 0.12 (0 to 0.38$)$ \\
\hline Non-permanent ('near miss') & 0.57 (0 to 1.21$)$ & 0.62 (0 to 2.01$)$ & 0.58 (0 to 1.16$)$ \\
\hline Not provided* & 0.09 (0 to 0.36$)$ & 0.21 (0 to 1.01$)$ & 0.12 (0 to 0.38$)$ \\
\hline Total ASCls & $0.90(0.09$ to 1.70$)$ & 5.34 (1.24 to 9.45$)$ & $1.73(0.72$ to 2.74$)$ \\
\hline \multicolumn{4}{|c|}{$\begin{array}{l}\text { Acute spinal cord injuries (ASCls) are divided into outcomes: not provided, non-permanent ('near misses') and permanent (neurological } \\
\text { deficit, quadriplegic and fatal). Incidences are shown for Junior, Senior and Combined (Junior+Senior). } \\
\text { *Specific diagnosis not available/supplied, but confirmed as ASCl. } \\
\text { Bold text indicates value is significantly different from Junior level: this occurs either if the } 95 \% \mathrm{Cl} \text { do not overlap or if the } p \text { value is less than } \\
0.05 \text {. }\end{array}$} \\
\hline
\end{tabular}



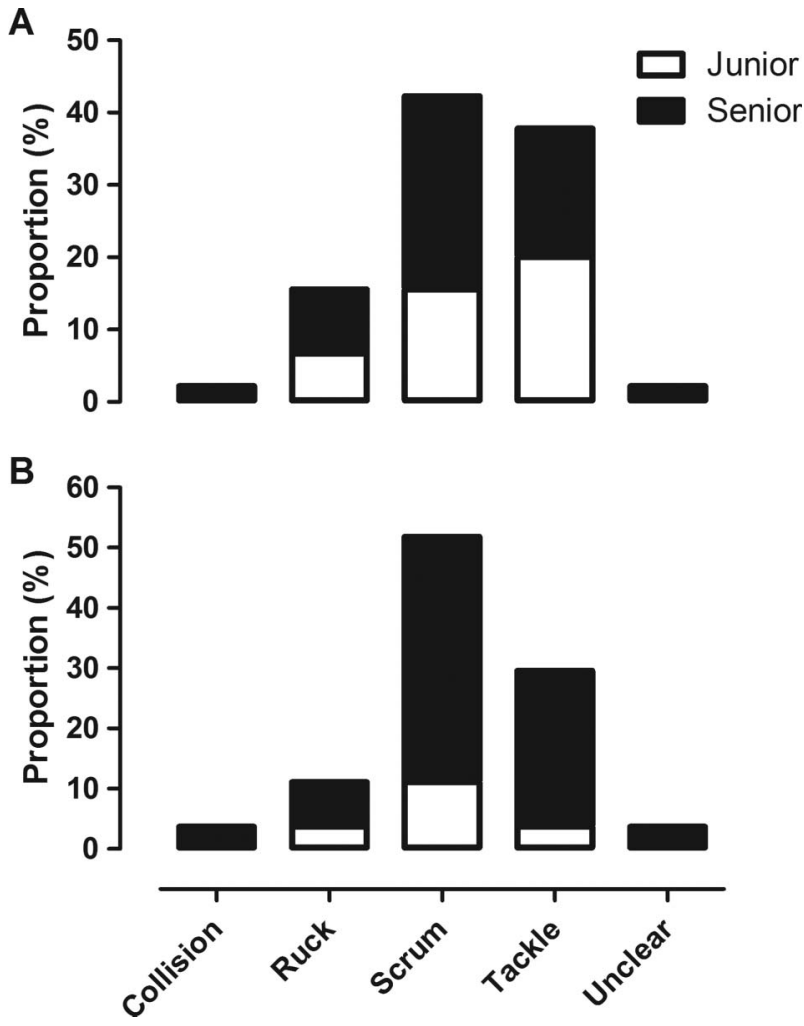

Figure 1 (A) The phase of play (Collision, Ruck, Scrum or Tackle) that accounted for all acute spinal cord injuries (ASCI) $(n=45)$ and $(B)$ permanent $A S C l$ outcomes at the Junior and Senior levels. Segments add up to $100 \%$.

scrum engagement and a collapsed scrum contributed to $56 \%$ and $39 \%$ of cases, respectively $(n=10$ and 7 of 18 , respectively; $\mathrm{n}=1$ case was attributed to popping out, and information was not provided for $n=1$ case). The tackle events were evenly split between the tackler and ball-carrier ( $\mathrm{n}=8$ for each).

For further analyses, only $n=40$ cases were considered because four cases occurred in positional groupings that are not the conventional 15-a-side rugby $(\mathrm{n}=3$ 'seven-a-side', n=1 Mini-rugby) and the event responsible was 'unclear' for one case.

The hooker and loose-forward positional groupings were associated with $38 \%(n=15$ of 40$)$ and $25 \% \quad(n=10$ of 40) of all ASCIs (figure 2A). Eighty per cent of all ASCIs to the hooker position were permanent injury outcomes $(n=12$ of 15$)$. Together, the hooker, prop and lock positional groupings (tight five) accounted for all the scrum injuries. The tackle injuries were shared between all positional groupings except prop and scrumhalf.

When examining permanent ASCIs in isolation (figure 2B), only the forward positional groupings were represented (prop, hooker, lock and loose-forward). Of these permanent outcomes, the hooker alone accounted for $46 \%(n=12$ of 26$)$ of all injuries, $83 \%$ of which $(n=10$ of 12) were as a result of the scrum. The loose-forward

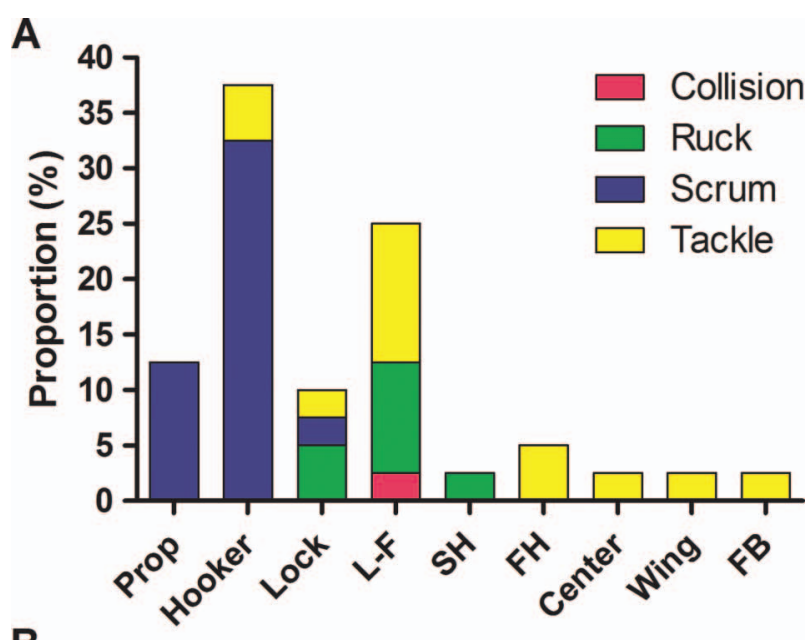

B

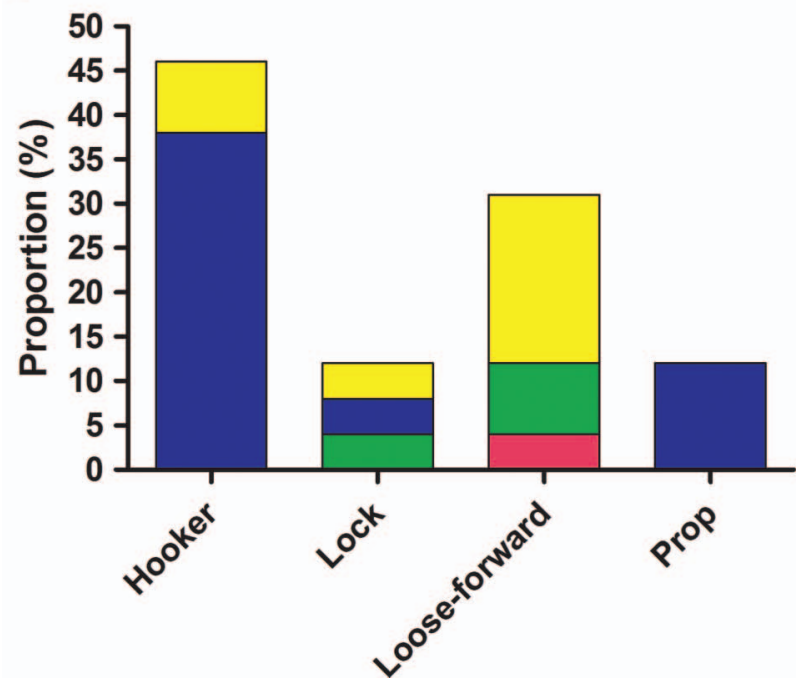

Figure 2 (A) The positional grouping, and the phase of play (tackle, scrum, ruck or collision) that accounted for all acute spinal cord injuries (ASCI) $(n=40)$ and $(B)$ permanent $\mathrm{ASCl}$ $(n=27)$ outcomes. For all $A S C l$ outcomes, four cases were excluded from the analysis as three were from seven-a-side rugby and one was from Mini rugby. One case was excluded from both all $\mathrm{ASCl}$ and permanent outcomes as the event was 'unclear'. All segments, in combination, add up to $100 \%$. L-F, Loose-Forward; FH, Flyhalf; SH, Scrumhalf.

positional grouping accounted for $31 \%$ ( $n=8$ of 26 ) of all permanent outcomes, $63 \%(n=5$ of 8$)$ of which came from the tackle.

\section{DISCUSSION}

In South Africa, we found that the average annual incidence of all rugby-related catastrophic outcomes (excluding cardiac events) was 2.00 per 100000 players (95\% CI 0.91 to 3.08) between 2008 and 2011. This is comparable to the rate reported for Argentina (1.90 per 100000 players) ${ }^{23}$ between 1977 and 1997 and Ireland (0.89 per 100000 players $)^{5}$ between 1995 and 2004. These are the only rugby-related catastrophic injury papers that included 'near miss' outcomes, and the incidences were only subsequently estimated by a recent 
review article. ${ }^{1}$ While the current consensus statement for rugby injury data collection recognises the importance of calculating incidences for comparability across playing nations, ${ }^{20}$ it still does not include 'near miss' outcomes in the definition of catastrophic injury. The small difference between non-permanent and permanent outcomes, and therefore the epidemiological importance of including these outcomes, has been stated by various authors in the past ${ }^{3}{ }^{24}$ and was clearly illustrated in a recent UK study of spinal injuries in junior players. ${ }^{25}$

For comparative purposes, the average annual incidence of permanent ASCIs and TBIs was 1.23 per 100000 players (95\% CI 0.38 to 2.08) between 2008 and 2011. On a Health and Safety Executive scale ${ }^{1}$ which categorises risk in ascending order, from 'negligible' (0.001-0.1 cases per 100000 population) to 'acceptable' (0.1-2.0 cases per 100000 population); 'tolerable' (2.0100.0 cases per 100000 population); and 'unacceptable' (>100 cases per 100000 population), this incidence would be classified as 'acceptable'. This average incidence is also comparable to the rates reported in a review of rugby-related permanently disabling head and spinal injuries ${ }^{1}$ in the UK $(0.48-1.50$ per 100000 players), but was on the lower end of rates reported for other countries (0.89-13.00 per 100000 players) in the same review. However, although this aforementioned review ${ }^{1}$ intended to include both permanent TBIs and ASCIs, the majority of studies that were included only investigated the latter type of injury.

Therefore, the average annual incidence of permanent ASCIs in the present study (1.04 per 100000 players, 95\% CI 0.25 to 1.82 ) is the more comparable incidence to those presented in the review. ${ }^{1}$ The incidence of permanent ASCIs in the present study is also similar to that reported for comparable outcomes in Australia between 1997 and 2002 (3.2 per 100000 players $)^{26}$ and New Zealand before (between 1.6 and 3.9, per 100000 players, per year) and after the introduction of RugbySmart (between 0.8 and 1.7, per 100000 players, per year). ${ }^{10}$ The incidence data of New Zealand is particularly believable and accurate due to their comprehensive no-fault insurance system. ${ }^{27}$ The annual average incidence of the present study is also greater than the estimated incidence of permanent spinal cord injuries for South Africa between 2001 and 2005 (0.6 per 100000 players), ${ }^{7}$ although the earlier study had a different method of data collection to that of the present.

For further comparison, the annual average incidence of non-fatal permanent ASCIs (excluding near misses and fatalities) for the present study was 0.92 per 100000 players (95\% CI 0.18 to 1.66 ), which is significantly lower than the rate reported for comparable outcomes (ASIA scale A-D, excluding fatalities) in Australia between 1995 and 2003 (6.8 per 100000 players, 95\% CI 4.0 to 10.7$),{ }^{28}$ but comparable to France before (2.1 per 100000 players, per year) and after the introduction of modified laws and guidelines for the scrum (1.4 per 100000 players, per year).
The main finding of the present study was the higher incidence of catastrophic injuries at the Senior level, in comparison with the Junior level. This associated factor, along with other relevant factors, is described in the following section.

\section{Senior (as opposed to Junior) level}

The novel conclusion of the present study is that the annual average incidence of all (including "near misses') and permanent ASCI outcomes between 2008 and 2011 was significantly higher at the Senior level than Junior level. Although incidences at the Senior level have previously not been statistically compared with those at the Junior level, the preceding literature in Australia $^{26}$ and France $^{29}$ have indeed also reported higher incidences in the Senior age group compared with Junior age group. The best comparison to the present study was an American Football study ${ }^{30}$ that investigated a comparable range of all ASCI outcomes per 100000 players: fatal to serious, with full recovery outcomes (equivalent to 'near miss' in the present study). This American Football study had similar annual average incidences per 100000 high school and college players, respectively, to the present study: 1.10 (present study: 0.90 per 100000 players, $95 \%$ CI 0.09 to 1.70 ) and 4.72 (present study: 5.34 per 100000 players, 95\% CI 1.24 to 9.45 ).

It was interesting to note that this study presents the first documented incidence of catastrophic injury in mini rugby, ${ }^{1}$ although this injury had a 'near miss' outcome.

The reason for the higher incidence rates at the Senior level may, in part, be related to more stringent law variations, in particular with respect to the scrum, at Junior levels. ${ }^{31}$ Under-19 law variations for the scrum include, but are not limited to: not being able to push a scrum more than $1.5 \mathrm{~m}$ and not being allowed to wheel a scrum. ${ }^{32}$ These law changes decreased the numbers of spinal cord injuries in New Zealand. ${ }^{33}$ However, the consistent finding that all (non-catastrophic as well as catastrophic) injury incidence rates are higher at the Senior level than Junior level ${ }^{34-36}$ suggests that this finding is not unexpected. Studies investigating general injuries have suggested that increased speed ${ }^{36}$ and increased competitiveness and aggression ${ }^{34} 35$ may be responsible for the differences in incidences at these levels. Other factors such as 'weekend warriors' (adults only playing sport at the weekend, without sufficient training, coaching and conditioning) and the low numbers of players at the senior level, which could force players to play in unfamiliar positions, are potential contributing factors, although these require further investigation.

\section{Hooker positional grouping}

While the many positional groupings of rugby do not allow for statistical comparisons, the hooker positional grouping accounted for the highest proportion of all ASCIs $(38 \%)$ in the present study, which is alarming 
considering the small proportion $(7 \%, \mathrm{n}=1$ of 15$)$ that this position represents in a traditional 15-man starting line-up. Furthermore, this finding and comparison has been made in previous research in South Africa ${ }^{7}$ and other countries. ${ }^{2}$ Moreover, this position also accounted for the majority of all permanent ASCIs (46\%) in the present study, regardless of the age group, and $83 \%$ of these $(n=10$ of 12$)$ were in the scrum.

While the findings could not be investigated statistically, common sense would argue that the large proportion of ASCIs attributed to this one specific playing position represents an alarming finding that is a matter for concern.

The Hooker's role and position in the scrum could place this player at more risk of suffering scrum-related ASCI than any other positional groupings. During engagement, the hooker has each arm bound around a prop, and is driven into the gap between the opposition hooker and prop by his/her teammates. During this period, and the subsequent shove, there are a number of forces experienced by the front-row including lateral, vertical and compressive. Depending on the level, the compressive forces can be between 8.7 and $16.5 \mathrm{kN} .{ }^{37} \mathrm{At}$ these large impulsive forces, with the hooker unable to adjust his/her position due to the scrum structure, a slight miscalculation or deliberate foul play could result in a catastrophic event to this player.

\section{Scrum (as opposed to any other phase of play)}

The scrum alone accounted for a rate of 0.73 ASCIs per 100000 players and for $42 \%$ of all ASCIs. The high proportion of scrum-related catastrophic injuries has previously been shown in South Africa ${ }^{7}$ and other countries ${ }^{21}$ Additionally, there was a higher proportion of scrumrelated catastrophic injuries in the present study (42\%) in comparison to other studies which also included 'near misses', for example, in Ireland (17\%, 2 of 12).$^{5}$

However, studies that only investigated permanent outcomes found that the scrum accounted for $37 \%$ (68 of 183 ) of all cases in South Africa, $51 \%$ (19 of 37) of all cases in France, and $61 \%$ of all cases in Argentina, ${ }^{23}$ which were comparable in proportion to that of the present study (52\%).

Independently, a higher proportion of scrum compared with tackle-related ASCIs resulted in permanent outcomes $(82 \%$ vs $50 \%)$. Considering that scrums occur relatively infrequently in comparison to tackles and rucks, ${ }^{38}$ these findings are noticeably understated.

While the hooker, prop and lock positional grouping (tight five) accounted for all the scrum-related permanent ASCIs, the tackle-related injuries were shared between all positional groupings except prop and scrumhalf, which represents the more generalised risk in the latter phase of play. While the incidence was not significantly different between age groups, $79 \%$ of all permanent scrum-related ASCIs occurred at the Senior level rather than the Junior level. The engagement sequence accounted for the largest proportion of scrum-related injuries $(56 \%)$ in the present study, which is consistent with previous findings, ${ }^{2} 39$ and has been attributed to the high forces experienced by the front row during this phase of the scrum. ${ }^{29} 40$ The high forces (and thus acceleration) during engagement would exacerbate any predisposing risk factor.

The premature degeneration of the cervical spine, particularly in front row players, ${ }^{10}{ }^{41}$ mismatches in size between front-row players, ${ }^{2}{ }^{12}$ and high impact forces ${ }^{4042}$ have been mentioned as potential factors for the relative over-representation of scrum-related injuries in the previous literature, but other factors such as refereeing experience, coaching experience, scrum laws, technical preparation, appropriate player selection and specific conditioning of players should also be scrutinised more carefully.

While the four phase 'crouch, touch, pause, engage' refereeing sequence has been shown to have some positive effect on injury incidences, ${ }^{39}$ the results of the present study warrant considering further law changes with potentially greater effect, especially for the amateur game. The modification of scrum laws/regulations in amateur rugby in France: removal of the high impact on engagement, linking the two packs together before the scrum commences and a 'rugby passport' licence to certify the capacity of front-row players significantly reduced scrum-related catastrophic cervical spine injuries, including those to the front-row and hooker positions. ${ }^{29}$ Furthermore, the exemplary nationwide injury prevention programme of New Zealand, RugbySmart, had a significant reduction in scrum-related spinal injuries, ${ }^{10}$ and it is hypothesised that the BokSmart programme can produce a similar effect over time. ${ }^{12}$ This paper serves as a reference point for the BokSmart programme going forward.

Although all ASCIs occurred to males in the present study, this may simply be an artefact of disproportionate participation levels: there are only 17917 females in comparison to 633229 males (http://www.irb.com/ unions/index.html).

The average annual incidence of cardiac death rates in the present study in Junior players $(0.05$ per 100000 players) is less than the rates published previously for competitive athletes younger than 18 years of age. ${ }^{42}$ There were no prospective incidences available for adult/senior populations.

\section{Limitations}

Player numbers were assumed to remain constant over the 4 years of investigation. While they may have fluctuated between years, it is unlikely that the numbers have declined appreciably, thereby ensuring that incidences were not underestimated. The estimation of player numbers (population at risk) may also be open to error. However, owing to the fact that these rare events are shown as an incidence per 100000 players, the inaccuracy would have to be enormous to affect the results presented in the current study. Furthermore, errors in 
numbers would probably be consistent at both levels (Junior and Senior) and should not drastically affect between-level comparisons.

It is plausible to suggest that some catastrophic events might not be reported to BokSmart and the CBPJPF. However, the Serious Injury Protocol, and the potential benefit of financial assistance that is associated with reporting injuries in South Africa, would make this possibility very small. Information dissemination via social media and other more formal communication channels regarding catastrophic rugby injuries would generally pick up any shortfall potentially missed.

\section{CONCLUSION}

In conclusion, the rates of all (including near-miss) and permanent (excluding near-miss) rugby-related ASCIs in South Africa from 2008 to 2011 are comparable to the rates in most other countries and to the rates in other collision sports such as American Football. Despite this finding, three factors were strongly associated with catastrophic injury and warrant further attention for prevention strategies: Senior players, hooker playing position and the scrum phase of play. This 4-year registry will serve as a reference point for the evaluation of the BokSmart injury prevention programme going forward.

Acknowledgements The authors would like to thank the board of the Chris Burger/Petro Jackson Player's Fund (CBPJPF) and especially the former Springbok captain, Morne Du Plessis, for his foresight in initiating the fund. The authors would also like to thank Ms Gail Ross, in her current position as Serious Injury Case Manager, for her dedication and effort in collecting the information that has been presented in this study.

Contributors JB was granted access to analyse the data, was involved in conceptualising the manuscript, conducted statistical analyses and wrote the initial drafts of the manuscript. He is also the guarantor. CR and WV collected and entered the data. All authors (ML, EV, CR, WM and WV) were involved in conceptualising and editing drafts of the paper, in the order that they appear on the author list.

Funding This research received no specific grant from any funding agency in the public, commercial or not-for-profit sectors.

Competing interests None.

Ethics approval UCT Human Ethics Committee.

Provenance and peer review Not commissioned; externally peer reviewed.

Data sharing statement Depersonalised data are available at the following URL: http://images.supersport.com/Website $\% 20$ Serious $\% 20$ injury $\% 20$ table $\%$ 20updated\%2031\%20December\%202011.pdf. Owing to the sensitive nature of the information and appropriate medical ethics, access to a more detailed aspect of the available dataset will be reviewed upon request and on a discretionary basis. Sharing of only depersonalised and non-relatable data will be considered, once permission has been received from WV or CR (can be contacted through the corresponding author).

\section{REFERENCES}

1. Fuller CW. Catastrophic injury in rugby union: is the level of risk acceptable? Sports Med 2008;38:975-86.

2. Quarrie KL, Cantu RC, Chalmers DJ. Rugby union injuries to the cervical spine and spinal cord. Sports Med 2002;32:633-53.

3. Noakes T, Jakoet I. Spinal cord injuries in rugby union players. BMJ $1995 ; 310: 1345-6$.
4. Banerjee R, Palumbo MA, Fadale PD. Catastrophic cervical spine injuries in the collision sport athlete, part 1: epidemiology, functional anatomy, and diagnosis. Am J Sports Med 2004;32:1077-87.

5. Shelly M, Butler J, Timlin M, et al. Spinal injuries in Irish rugby: a ten-year review. J Bone Joint Surg Br 2006;88:771.

6. Brooks JHM, Kemp SPT. Recent trends in rugby union injuries. Clin Sports Med 2008;27:51-73.

7. Hermanus FJ, Draper CE, Noakes TD. Spinal cord injuries in South African Rugby Union (1980-2007). S Afr Med J 2010; 100:230-4.

8. Kew T, Noakes TD, Kettles AN, et al. A retrospective study of spinal cord injuries in Cape Province rugby players, 1963-1989. S Afr Med J 1991;80:127-33.

9. Noakes TD, Draper CE. Preventing spinal cord injuries in rugby union. BMJ 2007;334:1122-3.

10. Quarrie KL, Gianotti SM, Hopkins WG, et al. Effect of nationwide injury prevention programme on serious spinal injuries in New Zealand rugby union: ecological study. BMJ 2007;334:1150.

11. Brooks JHM, Fuller CW. The influence of methodological issues on the results and conclusions from epidemiological studies of sports injuries: illustrative examples. Sports Med 2006;36:459-72.

12. Viljoen W, Patricios J. BokSmart-implementing a National Rugby Safety Programme. Br J Sports Med 2012;46:692-3.

13. Brown J. The introduction of an international model to reduce injuries in Rugby Union in South Africa. South Afr J Sports Med 2011;23:62-3

14. Finch CF, Donaldson A. A sports setting matrix for understanding the implementation context for community sport. Br J Sports Med 2010;44:973-8.

15. van Mechelen W, Hlobil H, Kemper H. Incidence, severity, aetiology and prevention of sports injuries. A review of concepts. Sports Med 1992;14:82-99.

16. Tebbutt P. Samaritan of South African Rugby. Sun Press, 2010.

17. Duthie G, Pyne D, Hooper S. Applied physiology and game analysis of rugby union. Sports Med 2003;33:973-91.

18. Durandt J, Toit Du S, Borresen J, et al. Fitness and body composition profiling of elite junior South African rugby players: original research article. South Afr J Sports Med 2006;18:46-51.

19. Knowles SB, Marshall SW, Guskiewicz KM. Issues in estimating risks and rates in sports injury research. J Athl Train 2006;41:207.

20. Fuller CW, Molloy MG, Bagate C, et al. Consensus statement on injury definitions and data collection procedures for studies of injuries in rugby union. Br J Sports Med 2007;41:328-31.

21. VRP Injury Software (Internet). http://www.iprc.unc.edu/ sportsinjurystatistics.shtml Injury Prevention Research Center. University of North Carolina (accessed Jan 2013).

22. Wolfe R, Hanley J. If we're so different, why do we keep overlapping? When 1 plus 1 doesn't make 2. CMAJ 2002;166:65-6.

23. Secin FP, Poggi EJ, Luzuriaga F, et al. Disabling injuries of the cervical spine in Argentine rugby over the last 20 years. $\mathrm{Br} J$ Sports Med 1999;33:33-6.

24. Rotem T, Lawson J, Wilson S. Severe cervical spinal cord injuries related to rugby union and league football in New South Wales, 1984-1996. Med J Aust 1998;168:379-81.

25. MacLean JG, Hutchison JD. Serious neck injuries in U19 rugby union players: an audit of admissions to spinal injury units in Great Britain and Ireland. Br J Sports Med 2012;46:591-4.

26. Carmody DJ, Taylor TKF, Parker DA, et al. Spinal cord injuries in Australian footballers 1997-2002. Med J Aust 2005; 182:561-4.

27. Gianotti SM, Quarrie KL, Hume PA. Evaluation of RugbySmart: a rugby union community injury prevention programme. J Sci Med Sport 2009;12:371-5.

28. Berry JG, Harrison JE, Yeo JD, et al. Cervical spinal cord injury in rugby union and rugby league: are incidence rates declining in NSW? Aust N Z J Public Health 2006;30:268-74.

29. Bohu Y, Julia M, Bagate C, et al. Declining incidence of catastrophic cervical spine injuries in French Rugby: 1996-2006. Am J Sports Med 2009;37:319-23.

30. Boden BP, Tacchetti RL, Cantu RC, et al. Catastrophic cervical spine injuries in high school and college football players. $A m \mathrm{~J}$ Sports Med 2006;34:1223-32.

31. Noakes T, Jakoet I, Baalbergen E. An apparent reduction in the incidence and severity of spinal cord injuries in schoolboy rugby players in the Western Cape since 1990. S Afr Med J 1999;89:540.

32. Board IR. IRB Laws of the Game (Internet). http://www.irb.com. (cited 2013 Jan 17). http://irblaws.com/index.php?variation=1 (accessed 1 Sept 2012). 
33. Burry HC, Calcinai CJ. The need to make rugby safer. BMJ (Clin Res Ed) 1988;296:149-50.

34. Bird YN, Waller AE, Marshall SW, et al. The New Zealand Rugby Injury and Performance Project: V. Epidemiology of a season of rugby injury. Br J Sports Med 1998;32:319-25.

35. Lee AJ, Garraway WM. Epidemiological comparison of injuries in school and senior club rugby. Br J Sports Med 1996; 30:213-17.

36. Roux C, Goedeke R, Visser G, et al. The epidemiology of schoolboy rugby injuries. S Afr Med J 1987;71:307-13.

37. Preatoni E, Stokes KA, England ME, et al. The influence of playing level on the biomechanical demands experienced by rugby union forwards during machine scrummaging. Scnd J Med Sci Sports 2013 (Epub ahead of print).

38. Board IR. IRB Junior World Championship 2011: statistical review and match analysis. http://www.irb.com/mm/document/newsmedia/ mediazone/02/04/47/13/2011jwcstatisticalreport.pdf, 2012:1-28. (accessed 1 Sep 2012)

39. Gianotti S, Hume PA, Hopkins WG, et al. Interim evaluation of the effect of a new scrum law on neck and back injuries in rugby union. Br J Sports Med 2008;42:427-30.

40. Milburn PD. Biomechanics of rugby union scrummaging. Technical and safety issues. Sports Med 1993;16:168-79.

41. Scher AT. Premature onset of degenerative disease of the cervical spine in rugby players. S Afr Med J 1990;77:557-8.

42. Maron BJ, Thompson PD, Ackerman MJ, et al. Recommendations and considerations related to preparticipation screening for cardiovascular abnormalities in competitive athletes: 2007 update: a scientific statement from the American Heart Association Council on Nutrition, Physical Activity, and Metabolism: endorsed by the American College of Cardiology Foundation. Circulation 2007;115:1643-55 